\title{
DISEÑO EXPERIMENTAL DE SISTEMAS MODULARES EN BASE A LA ICONOGRAFÍA DE LA CERÁMICA PURUHÁ.
}

EXPERIMENTAL DESIGN OF MODULAR SYSTEMS BASED ON THE ICONOGRAPHY OF PURUHÁ CERAMICS.

\section{RESUMEN}

Los vestigios de la cultura Puruhá se estudian desde diversas aristas, principalmente desde el enfoque arqueológico. La última investigación formal data de 1927, realizada por Jijón y Caamaño. Desde el enfoque del Diseño, existen pocos antecedentes, considerando pertinente su análisis porque, entre los objetivos de esta disciplina, está el promover industrias culturales y particularmente, procesos para la digitalización de bienes culturales. La investigación surge con base al análisis de elementos visuales de piezas cerámicas, bajo la perspectiva de interpretación semiótica, basada en aportes teóricos de los autores Josef Estermann, Carlos Milla y Zadir Mi1la. El objetivo es desarrollar propuestas de sistemas modulares y súper modulares, aplicando leyes y categorías compositivas del Diseño. El método predominante es el analítico descriptivo, que parte de la digitalización de las piezas cerámicas seleccionadas, aplicando bipartición y tripartición armónica, principios compositivos propios de la semiótica andina. El proceso continúa con la aplicación de una matriz de generación modular, sustentada en leyes y categorías del Diseño. El resultado principal es el banco digital de sistemas modulares y súper modulares, que podrían ser utilizados como fuente inagotable de experimentaciones creativas para la creación de piezas gráficas, que evidenciarán la riqueza iconográfica de la cultura estudiada.

Palabras clave: Puruhá, sistemas modulares, iconografía andina, semiótica andina.

\section{ABSTRACT}

The vestiges of the Puruhá culture are studied from various angles, mainly from the archaeological point of view. The last formal investigation dates back to 1927, carried out by Jijón y Caamaño. From the approach of the Design, there are few antecedents, considering its analysis pertinent because, among the objectives of this discipline, it is to promote cultural industries and particularly, processes for the digitalization of cultural goods. The investigation arises based on the analysis of visual elements of ceramic pieces, under the perspective of semiotic interpretation, based on theoretical contributions of the authors: Josef Estermann, Carlos Milla and Zadir Milla. The objective is to develop proposals for modular and super modular systems, applying laws and compositional categories of Design. The predominant method is the descriptive analytic; part of the digitalization of the selected ceramic pieces, applying bipartition and harmonic tripartition, compositional principles typical of Andean semiotics. The process continues with the application of a modular generation matrix, based on laws and design categories. The main result is the digital bank of modular and super modular systems, which could be used as an inexhaustible source of creative experimentation for the creation of graphic pieces, which will show the iconographic richness of the studied culture.

Keywords: Puruhá, modular systems, Andean iconography, Andean semiotics

Jhoanna Katherine Vallejo Moreno

johannakvallejo@gmail.com

Universidad Nacional de Chimborazo

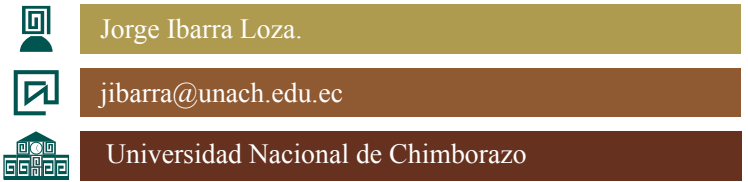

Universidad Nacional de Chimborazo 


\section{INTRODUCCIÓN}

El Ecuador es un país pluricultural y multiétnico, rico en elementos visuales, con alta carga semiótica, que no se han desvanecido a lo largo del tiempo, gracias a la presencia de vestigios, primordialmente arqueológicos. La cultura Puruhá se desarrolló en el Periodo de Integración entre los años $500 \mathrm{~d}$. C a 1500 d. C. En la actualidad, existen estudios recientes realizados en el cerro Collay, Riobamba, que citan que la cronología de esta cultura data, entre finales del periodo Formativo Tardío 700 a. C. e inicios del periodo de Desarrollo Regional, 500 d. C (Carretero y Samaniego 2017).

Se desarrolló en las provincias que actualmente son: Bolívar, Tungurahua Cotopaxi, y Chimborazo, siendo esta última, conocida como cuna de la nacionalidad Puruhá, por su valor arqueológico. Se cita que esta cultura estuvo bajo influencia incaica, antes que española, generando un sincretismo que hasta la actualidad se mantiene; esto según estudios publicados por el arqueólogo Jacinto Jijón y Caamaño en el año 1927, que tienen por título Puruhá, contribución al conocimiento de los aborígenes de la provincia de Chimborazo y la república del Ecuador. El texto divide a la cultura en siete periodos que son: Proto-Panzaleo I, Proto-Panzaleo II, Tuncahuan, Guano o San Sebastián, Elén pata, Huavalac y Puruhá incaico (Jijón y Caamaño 1927:3-9).

Hay que considerar que, al hablar sobre cultura Puruhá, el mayor referente es Caamaño, ya que sus estudios arqueológicos han sido tomados como base por varios autores como, Silvio Haro (1977) y Aquiles Pérez (1978).

El Diseño Gráfico como disciplina, se alinea al objetivo $\mathrm{N}^{\circ} 5$ del Plan Nacional del Buen Vivir, que establece "construir espacios de encuentro común y fortalecer la identidad nacional, las identidades diversas, la plurinacionalidad y la interculturalidad". Particularmente, la investigación se coloca en los literales: 5.2a. Fomentar el diálogo de saberes entre la comunidad y la academia, en la investigación y documentación de la memoria social, el patrimonio cultural y los conocimientos diversos. 5.2 b. Incentivar y difundir estudios y proyectos interdisciplinarios y transdisciplinarios sobre diversas culturas, identidades y patrimonios, con la finalidad de garantizar el legado a futuras generaciones. 5.4b. Generar mecanismos de información e investigación sectorial vinculados con las industrias culturales y creativas, la economía de la cultura y otros ámbitos de información que visibilicen el aporte económico de la cultura a nivel nacional. $5.4 \mathrm{~d}$. Estimular la creación, la producción, la difusión, la comercialización, la distribución, la exhibición y el fortalecimiento de emprendimientos e industrias culturales y creativas diversas, como sector estratégico en el marco de la integración regional.

Como diseñadores gráficos, es importante considerar estas políticas, con la visión de generar propuestas gráficas que comuniquen mensajes, utilizando códigos, símbolos y elementos propios de la cosmovisión andina y concretamente de las culturas ecuatorianas. La comunicación visual, permite al emisor generar contenidos que puedan ser fácilmente decodificados por el receptor, para lo cual es importante reflexionar en el contexto cultural y social en el que este se desempeña. La investigación se enmarca en el concepto de cultura como, conjunto de rasgos, materiales, e intelectuales distintivos, que caracterizan una sociedad o un grupo social, (Benítez y Garcés 1988). La cultura produce percepciones culturales que se diferencian de acuerdo a un contexto que se determina por la estratificación social, económica, agrícola etc., de las sociedades o grupos sociales. Además, contempla el concepto que define a la cultura como dependiente de la simbolización.

Según Kottak, la cultura se originó cuando los ancestros adquirieron la habilidad de usar símbolos y dar significado a una cosa o evento (2011). Las agrupaciones humanas, al dar una significación a un objeto o 
eventualidad, están trasmitiendo su cultura, por tal motivo, se hace necesario difundir las costumbres, ideología, símbolos y patrones culturales andinos.

Por otro lado, la semiótica como ciencia que estudia los signos, ayudó a la investigación para una mejor comprensión de las piezas de cerámica de la cultura Puruhá. Saussure habla de la Semiótica dentro del estructuralismo lingüístico como "la vida de los signos dentro de la sociedad en la que viven" (Saussure citado en Ferrer y Gómez 2013:11). Es decir, como los signos desarrollan diferentes significaciones en diferentes contextos sociales y temporales. Mientras que Pierce, plantea a la semiótica como "ciencia del pensamiento" (Pierce citado en Ferrer y Gómez 2013:12), todo lo que pueda ser representado o ideado por el pensamiento debe ser considerado como signo que tiene un significado y una representación.

La investigación considera los conceptos citados como contexto para el análisis semiótico. Y se alinea al concepto citado por Eco (1976) que explica a la semiótica como la disciplina que estudia los procesos de comunicación, para lo cual se establece sistemas de significación, en los están inmiscuidos criterios de la propia cultura; ya que está llena de símbolos, signos y significados que pueden ser decodificados por parte de los habitantes de estas culturas.

Cabe resaltar que, el campo de acción Chimborazo, es parte del contexto andino, por tanto, se consideró primordialmente los enfoques de la semiótica andina, sustentados por los autores: Josef Estermann, Carlos Milla y Zadir Milla. En este sentido, se considera a la semiótica como la disciplina que tiene por objeto la interpretación de símbolos a partir de la observación de fenómenos, dentro de un contexto cultural, es decir, estudia las manifestaciones del arte precolombino (Milla 1986). El desarrollo de las ilustraciones corresponde a un análisis morfológico semiótico, aplicando sistemas constructivos $\mathrm{y} / \mathrm{o}$ compositivos de bipartición y tripartición armónica, propuestos por Zadir Milla, más no corresponde a una ilustración arqueológica. Tomando esto como referencia y mediante la creación de fichas de análisis semiótico, se logró interpretar y abstraer signos y símbolos de las manifestaciones iconográficas andinas de la cultura Puruhá.

Para el proceso de construcción de módulos y súper módulos, los autores aplican las leyes de la Gestalt: buena forma, forma y fondo, cierre, contraste, proximidad, similitud, continuidad y movimiento o destino común; propuestas por Wertreimer, Kohler y Koffka en 1923(citado en Salguero 2018) y consideradas dentro de la enseñanza del Diseño, en la Escuela de la Bauhaus, bajo la dirección de Thomas Maldonado en 1927.

Estas leyes describen variantes de la percepción, en función a distintos estímulos visuales. Para dotar al diseño de lógica y generar una composición ordenada, bajo principios básicos de diseño, se utilizaron las categorías compositivas, logrando unidad visual. (Idrobo 2006). El objetivo principal fue desarrollar propuestas de sistemas modulares y súper modulares, aplicando citadas leyes y categorías compositivas del Diseño. Esta base de íconos, permitirán a futuro, desarrollar propuestas visuales que evidencien la riqueza iconográfica de la cultura Puruhá, en propuestas de diseño contemporáneo.

\section{METODOLOGÍA}

El manuscrito corresponde a un artículo de investigación, donde se emplean los siguientes métodos y materiales para la recolección de información.

La etnografía es considerada como la "ciencia que tiene por objeto el estudio y descripción de los pueblos con el fin de descubrir su sentido de vida, el sentido y la cosmovisión o visión del mundo que han construido históricamente y que siguen construyendo en medio de la interacción constante del lenguaje cotidiano" (Martínez citado en Salguero 2015:2). Para el caso, se utiliza el método etnográfico para el análisis de los vestigios cerámicos, que constituyen un fiel testimonio de las vivencias, tradiciones y/o expresiones propias de la cultura Puruhá. 
Como método teórico utiliza el histórico lógico; a decir de González (2015) este método permite consolidar una visión ordenada cronológicamente de un fenómeno, en determinado contexto. Para el caso, se analiza los vestigios cerámicos clasificados en los periodos propios de la cultura: Proto-Panzaleo I, Proto-Panzaleo II, Tuncahuan, Guano o San Sebastián, Elén pata, Huavalac y Puruhá incaico (Jijón y Caamaño 1997:3-9). En los textos de citado autor, se encuentran 117 láminas ilustradas de piezas cerámicas, en las que se obtuvo elementos visuales útiles para el estudio.

Hernández, citando a Danke afirma que "los estudios analíticos descriptivos buscan especificar las propiedades, las características y los perfiles importantes de personas, gru- pos comunidades o cualquier otro fenómeno que es sometido a un análisis" (Hernández, Fernández y Baptista citado en Pereira 2011:23). En el caso de estudio, se describieron las piezas seleccionadas, para lo cual se utilizó una tabla inventario, que permitió, mediante la técnica de observación, descartar láminas de piezas cerámicas con carencia de elementos visuales. Al poseer un número extenso de material a analizar, se trabajó una línea de tiempo, misma que tomó como base la división cronológica de los siete periodos culturales propuestos por Caamaño. Esto con el fin de reducir el número del material a estudiar, dejando como resultado, 30 láminas que están descritas en la tabla 1, que se priorizaron para la investigación.

Tabla 1. Selección del material de estudio según los periodos culturales de la cultura Puruhá.

\begin{tabular}{ccccc}
\hline Periodo & $\begin{array}{c}\text { Láminas con } \\
\text { elementos } \\
\text { visuales }\end{array}$ & $\begin{array}{c}\text { Número } \\
\text { de láminas }\end{array}$ & Láminas escogidas \\
\hline $\mathbf{1}$ & Proto Panzaleo I & 2 & 1 & 6 \\
\hline $\mathbf{2}$ & Proto Panzaleo II & 5 & 3 & 8,10 \\
\hline $\mathbf{3}$ & Tuncahuan & 6 & 3 & $15,16,17$ \\
\hline $\mathbf{4}$ & San Sebastián & 8 & 3 & $32,33,38$ \\
\hline $\mathbf{5}$ & Elén Pata & 37 & 18 & $40,41,42,43,45,47,51,53,54$, \\
\hline $\mathbf{6}$ & Huavalac & 5 & 2 & $95,56,58,61,62,67,69,70,73$. \\
\hline $\mathbf{7}$ & Puruhá Incaico & 2 & 1 & $93,101$. \\
\hline & Total & $\mathbf{7 0}$ & $\mathbf{3 0}$ & 106 \\
\hline
\end{tabular}

FUENTE: Elaboración propia con base en (Jijón y Caamaño 1927).

En lo que respecta a materiales, se utilizó fichas de análisis semiótico, que sirvieron para conocer las significaciones de los elementos presentes en las piezas cerámicas. Además, mediante el uso de las mismas, se logró la digitalización de dichos elementos, creando un banco digital útil para la experimentación en el Diseño.
Adicionalmente se trabajó con una matriz de generación modular, en la que se utilizó leyes y categorías del diseño, que permitan un desarrollo técnico del objetivo de la investigación. Se aplicó teorías del diseño bidimensional planteados por Wong (2004). También se aplicó las leyes de la Gestalt, detalladas en el acápite de introducción. Destaca la uti- 
lización de la ley de la adyacencia, misma que presenta múltiples posibilidades para generar varias propuestas. Esta ley, conjugada en ciertos casos con otras leyes, permitió la generación de nuevos módulos. Para los supermódulos se trabajó con categorías compositivas en estructuras modulares activas e inactivas con enrejados básicos, experimentando con criterios como: dirección, ritmo, movimiento, simetría y equilibrio. Por último, para la aplicación cromática, se tomó en consideración el soporte en el que se va a aplicar el diseño, dentro de un contexto contemporáneo.

\section{RESULTADOS Y DISCUSIÓN}

Como resultados relevantes del proceso de investigación se consideran, en primer lugar, el proceso metodológico para la abstracción semiótica e ilustración de íconos con base al análisis de piezas cerámicas, basadas en composiciones de bipartición y tripartición andina. En segundo lugar, el proceso creativo técnico para el desarrollo de módulos y súper módulos, aplicando leyes y principios compositivos y en tercer lugar el desarrollo creativo de piezas gráficas experimentales, aplicando los módulos y súper módulos generados, en elementos contemporáneos para el segmento de mercado de jóvenes.

Como parte del primer resultado, se considera el inventario de piezas cerámicas, que se ilustra en la tabla 1, de primordial importancia para delimitar el material de estudio, es decir, las piezas cerámicas con presencia de elementos visuales. Al respecto es importante señalar que fueron descartadas las fichas de piezas cerámicas que no tenían presencia de iconografía, utilizando la técnica de observación, en las láminas de los libros de Jijón y Caamaño (1927).

Criterios semióticos y semánticos para la abstracción semiótica e ilustración de íconos.

Se desarrolla como metodología la ficha de análisis semiótico, utilizada para recolectar datos relevantes como: periodo, cronología, técnica utilizada para la decoración. Además, las fichas permitieron determinar el tipo de trazado armónico y la digitalización de los módulos. Cabe resaltar que el proceso es gráfico, no obedece a criterios de la Arqueología, sino que constituye una digitalización formal de las piezas analizadas, bajo parámetros técnicos propios del Diseño, basados en sistemas compositivos de la semiótica andina.

La ficha consta de tres filas y dos columnas. En la fila uno, se visualiza la imagen del elemento a estudiar, seguido, se encuentra la información relevante, además de una breve descripción de la pieza cerámica. En la fila número dos, se visualiza la digitalización de la pieza cerámica y se describe el tipo de trazado armónico, en base criterios propuestos por Milla: trazado armónico binario y el trazado armónico terciario. La fila tres es la más amplia, al lado izquierdo encontramos la digitalización de los módulos, según el trazado armónico anteriormente propuesto y, en el lado derecho, se cita la interpretación semiótica, justificados teóricamente en el texto de Zadir Milla (1990).

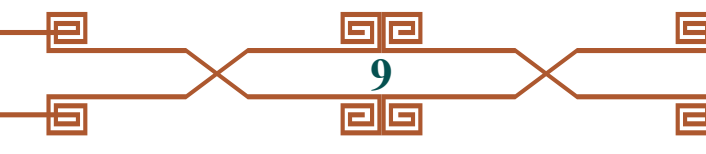


Tabla 2: Ficha de anảlisis semiótico
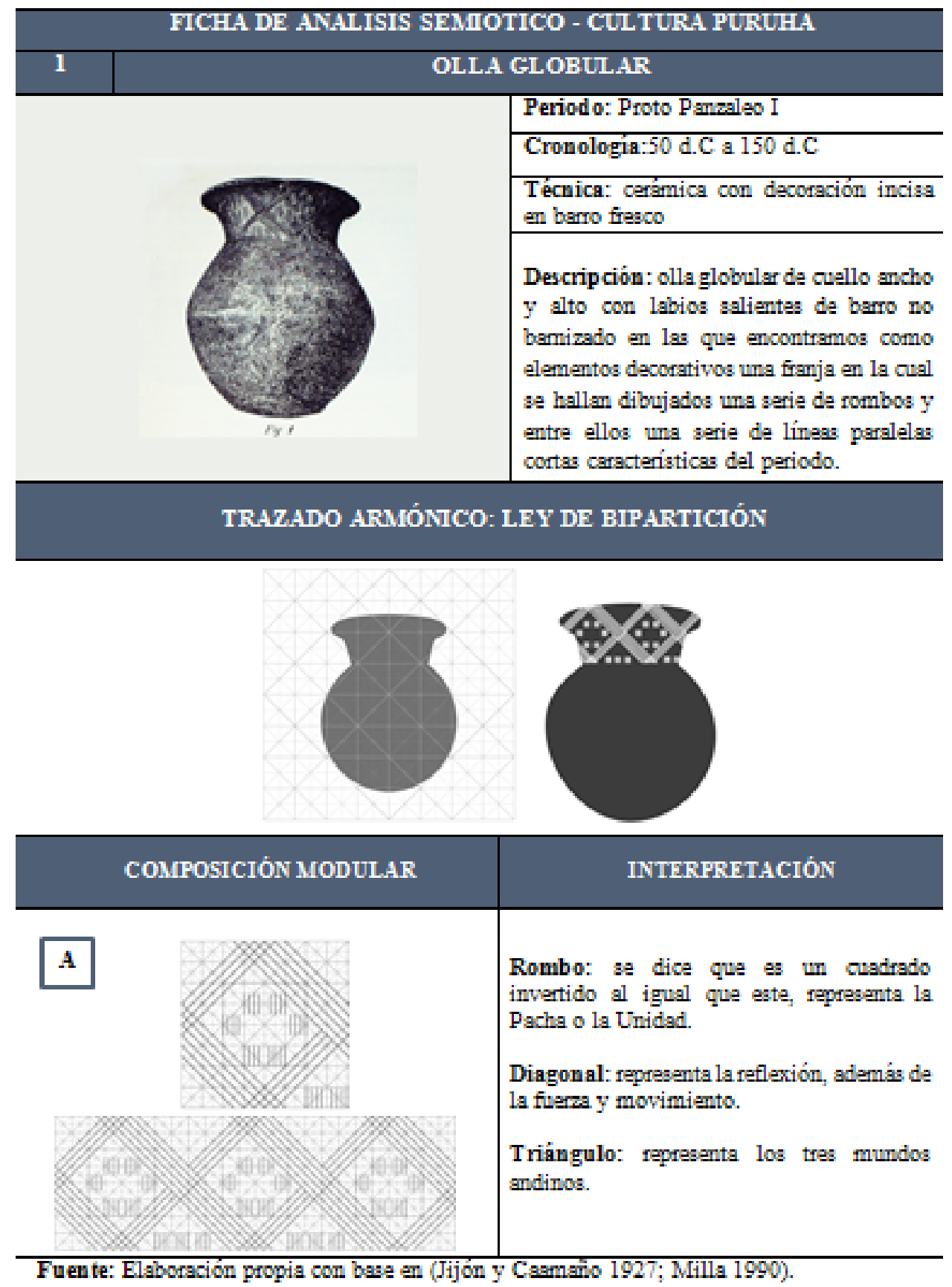

\section{Matriz de generación modular}

Esta matriz, sigue una metodología secuencial para la creación de nuevos módulos y súper módulos, como se puede apreciar en la figura 1, la misma consta de seis columnas y dos filas. En la primera columna encontramos el módulo tomado del banco de las piezas de estudio. En la segunda columna se realiza un proceso de abstracción modular. En la tercera, se trabajó bajo la ley de la adyacencia, para la creación del módulo. En la cuarta columna se aplicó las categorías compositivas, para la generación de los supermódulos. En la quinta, que corresponde a la aplicación cromática, se consideró el soporte a utilizar y, en la última columna, se encuentra la seriación de los módulos, para tener como resultado el súper módulo en una estructura modular activa e inactiva en ciertos casos. 
Figura 1: Matriz de generación de módulos y súper módulos, cultura Puruhá.

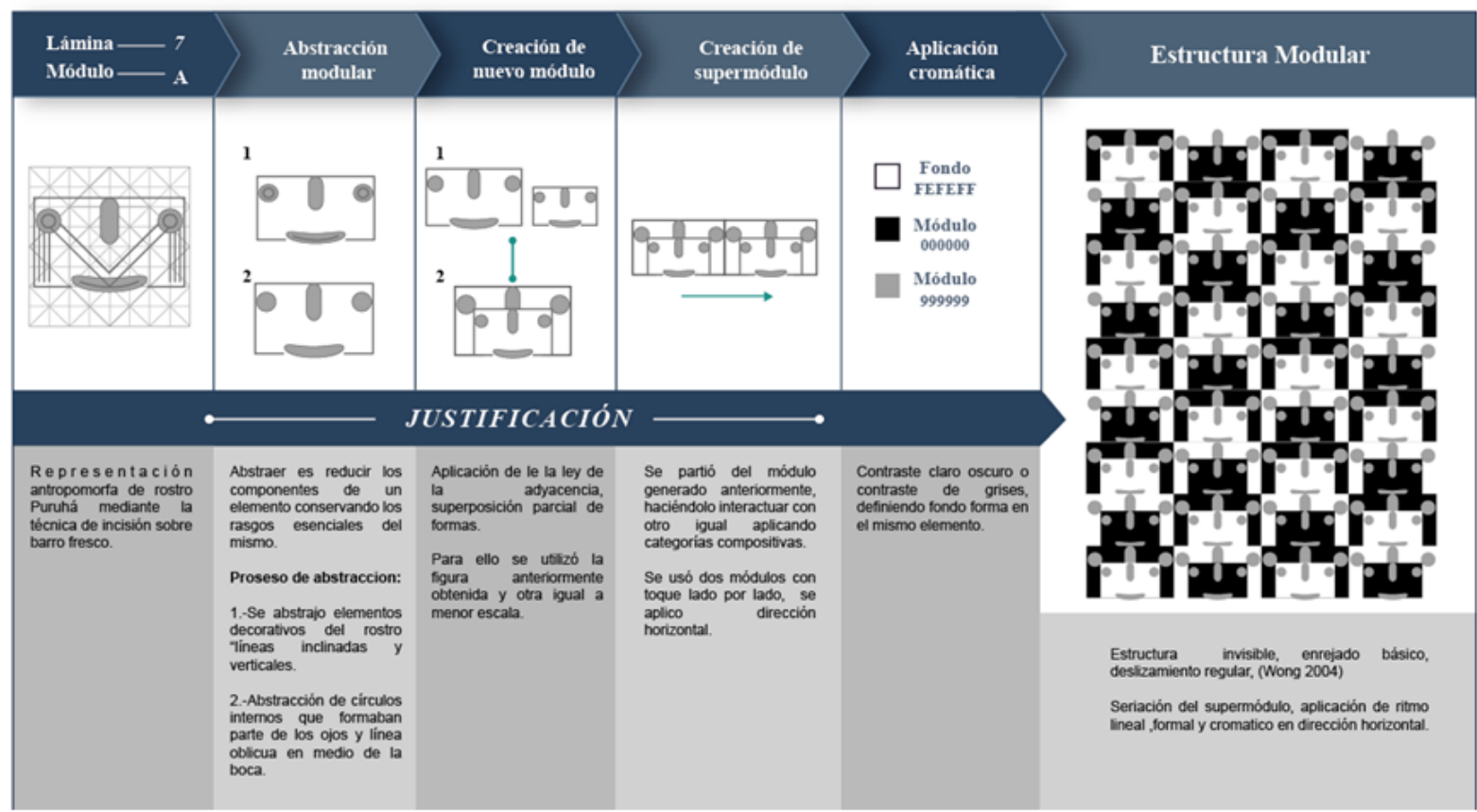

FUENTE: Elaboración propia a partir de los datos obtenidos en la Tabla 2.

$\mathrm{Al}$ respecto es importante tener en cuenta que se puede entender como sistemas modulares a las estructuras básicas que permiten la experimentación entre sí, generando un todo integrado, además es la unidad básica y funcional que tiene una composición (Wong 2004), Al respecto y como resultado de la investigación se experimentó con 10 módulos, en un proceso creativo que evidencia, como la iconografía presente en vestigios cerámicos de la Cultura Puruhá, puede ser utilizado en diseños contemporáneos.

La presencia de esta iconografía, en elementos o indumentarias propias de los jóvenes, traen a debate el origen de los mismos, logrando así, poner en valor, el diseño con identidad. Además, permite visualizar las expresiones culturales de tiempos pasados, en piezas visuales modernas; generando competencia en la atmósfera visual, a iconografía de contextos norteamericanos o europeos.

La experimentación mediante criterios técnicos, favorece que los diseñadores gráficos no limiten su capacidad creativa, utilizando recursos visuales propios de las culturas originarias ecuatorianas, planteando así, el uso de íconos con significaciones andinas, lo que favorece la difusión y reconocimiento de las mismas. En este caso, se realizó el estudio de la iconografía de la cerámica Puruhá, para utilizar como base en la creación de nuevos módulos y súper módulos. En el ámbito de la innovación, se puede replicar esta metodología para realizar investigaciones de distintas culturas precolombinas, para llegar a resultados óptimos, similares a los obtenidos en la presente investigación.

\section{Significados y significantes relevantes de las piezas analizadas}

Mediante el análisis efectuado con las fichas de análisis semiótico, se observó que en las piezas cerámicas predominan los cántaros antropomorfos, pertenecientes mayormente al periodo Elén Pata. En ellos se visualizan íconos representativos como: triángulos, diagonales, espirales, espirales dobles, círculos; además de representaciones del Sol, considerado por los habitantes de esta cultura como deidad. Así mismo, en las compoteras se encuentran representadas espirales, triángulos y círculos.

En las representaciones de timbales, destaca el ícono de un ave, que representa a un cóndor empollando. El cóndor como habitante del Hanan Pacha, es el encargado de vigilar y cuidar a los habitantes del medio mundo o Kay Pacha. En las ollas globulares se puede ver decoraciones con triángulos y círculos que simulan ojos, además, íconos que representan al Sol y a la 
serpiente. En las primeras manifestaciones de cerámica pertenecientes al periodo Proto Panzaleo I, se encuentran decoraciones incisas realizadas con la técnica del peine, en las que destacan grupos de líneas verticales y chevrones. Cabe mencionar que se trató de un análisis semiótico iconográfico mas no cromático, ya que, al tratarse de piezas ilustradas no se puede apreciar la cromática de las mismas. También es importante mencionar que, si bien se habla de una cromática policroma en la que se utilizaron colores como rojo, negro, y blanco, en ningún otro texto se hace mención sobre la significación y el porqué de la utilización de este tipo de pigmentos.

El conocimiento sobre criterios de semiótica y filosofía andina, permitieron la creación de módulos con significaciones andinas, que comuniquen la cosmovisión de esta cultura, utilizando para ello soportes dentro del diseño que permitan la difusión de los resultados de la investigación.

\section{Creación de banco de módulos y súper mó- dulos de las piezas seleccionadas}

Basados en la visión filosófica de Josef Estermann, Carlos Milla y Zadir Milla y considerando las leyes compositivas explicadas anteriormente, los autores de la presente investigación, desarrollaron un análisis semiótico descriptivo, de los elementos visuales presentes en las 30 láminas seleccionadas, según se puede apreciar en la tabla 3.

En cada figura se siguió el mismo proceso metodológico: ilustración formal creativa, abstracción geométrica basada en bipartición o tripartición, formulación icónica basada en una interpretación de significaciones y descripción formal, apegada a la fundamentación teórica de los autores citados.

Tabla 3: Banco digital de módulos

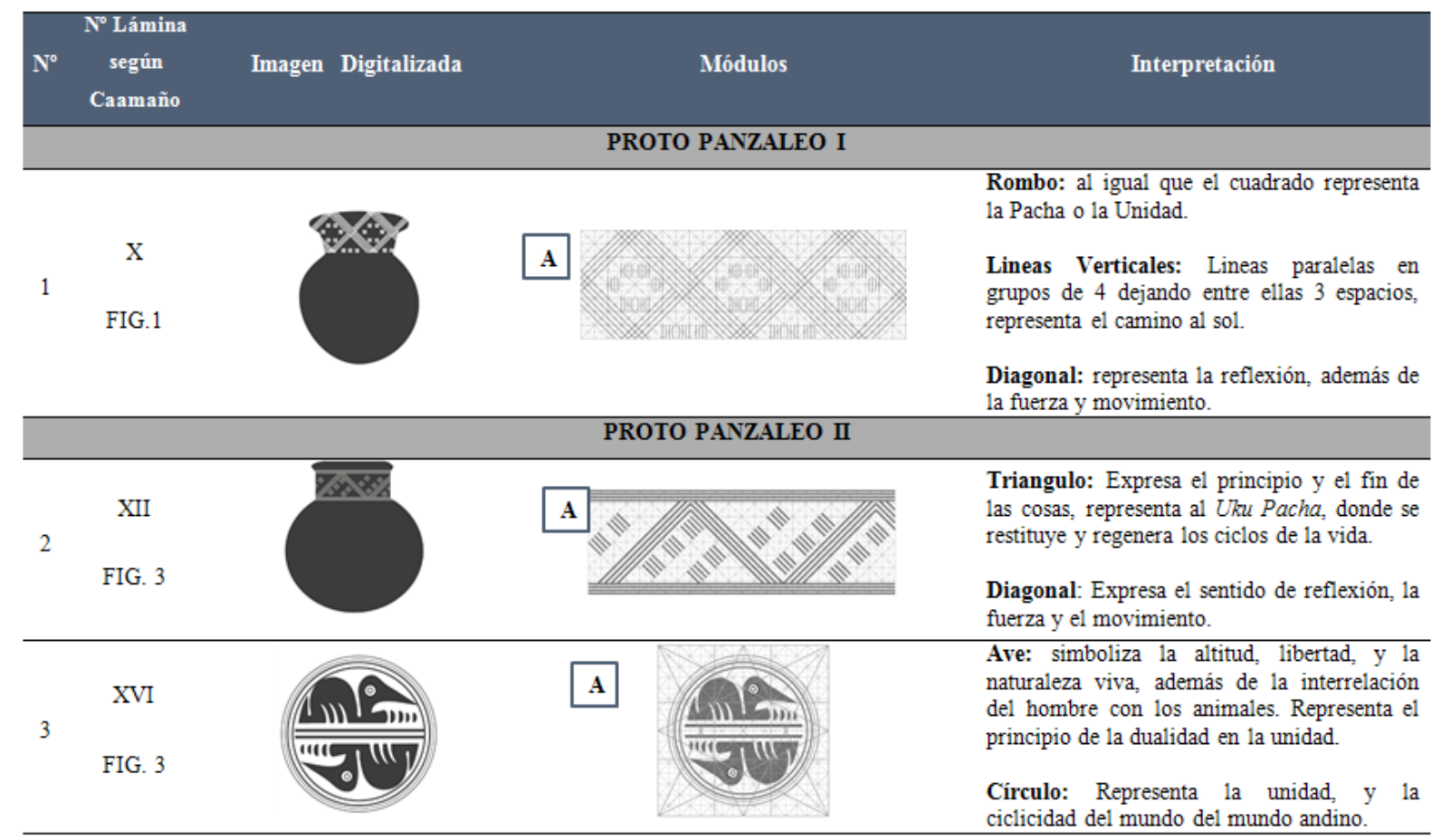




XXII $\quad$ XXII

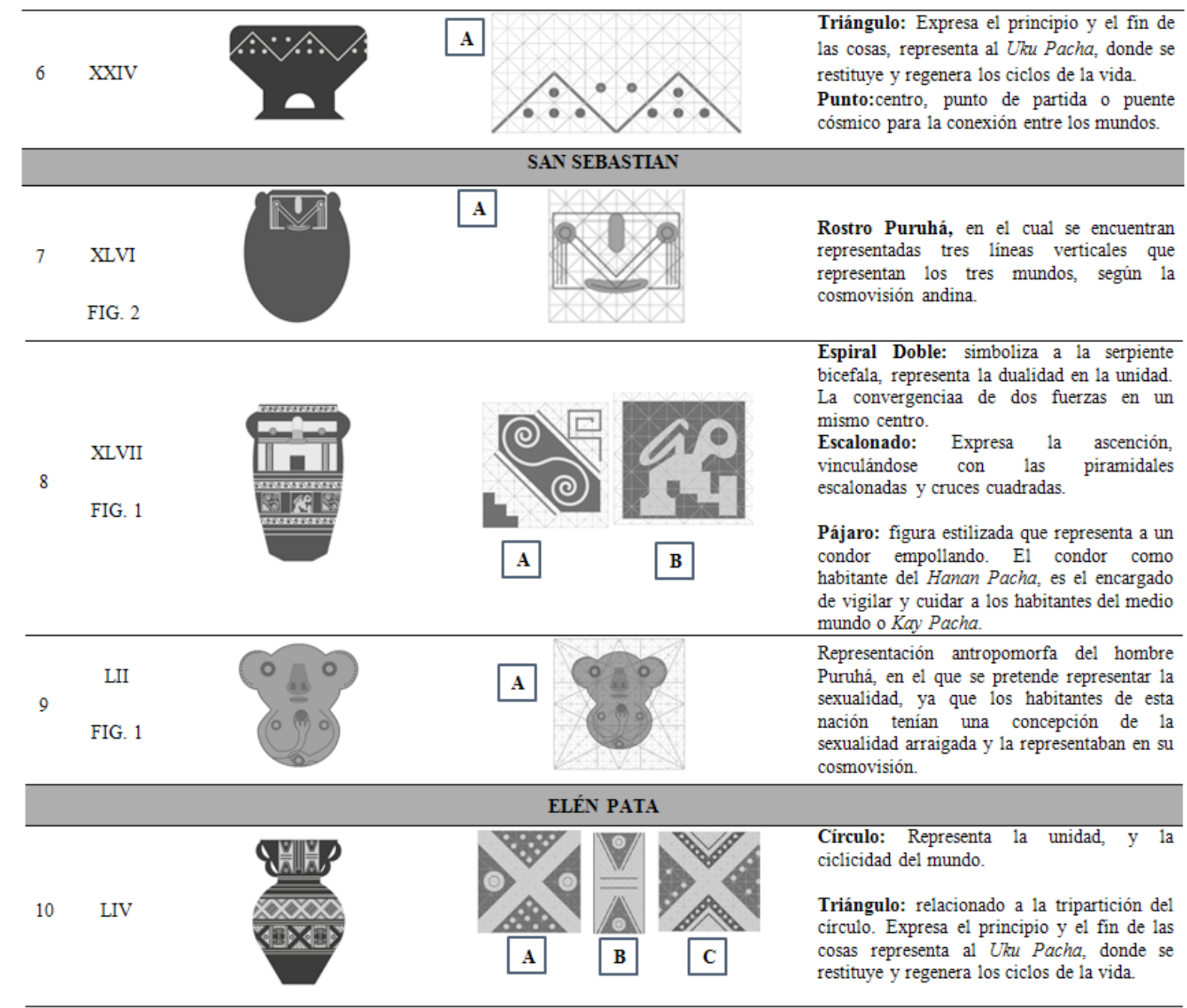




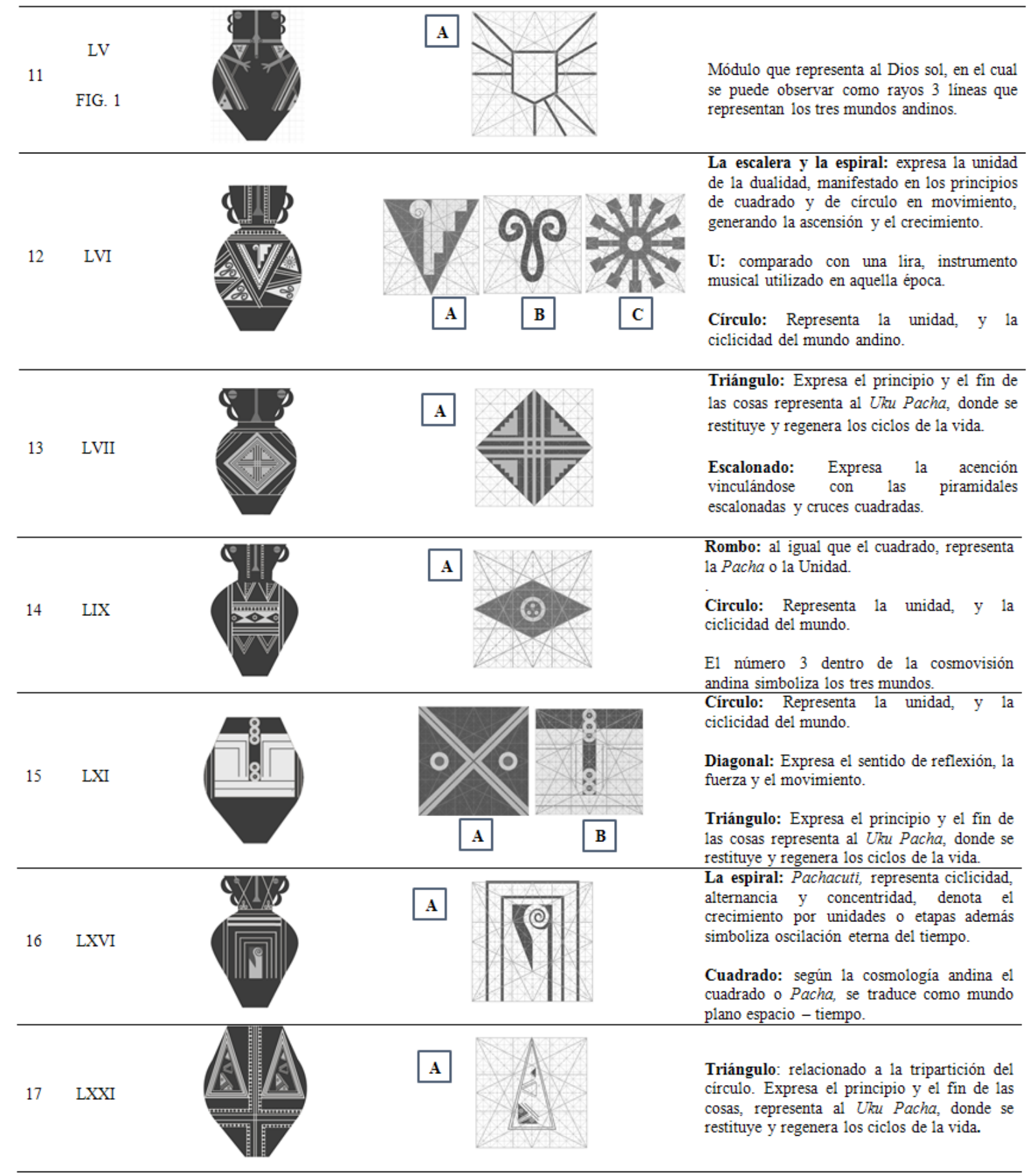




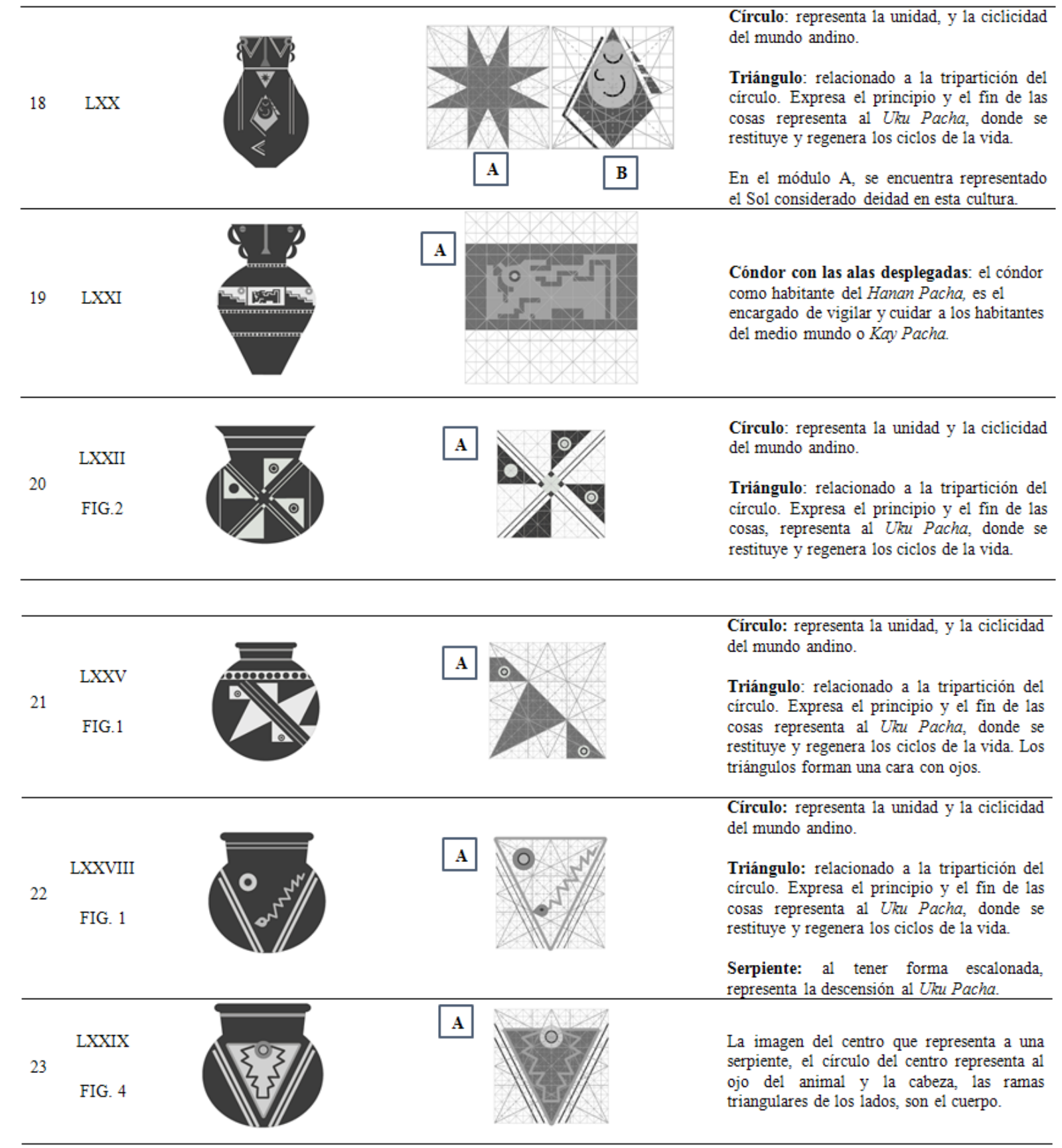




24 LXXXV

25 FIG. 3 (axxiII

26 FXXXIX

27 XII 2

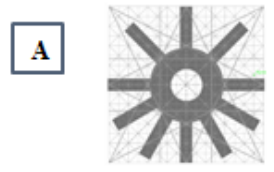

Figura de un animal marino: de cuerpo escalonado y cabeza con tentáculos

Círculo: representa la unidad, y la ciclicidad del mundo andino. Figura que representa al dios sol.

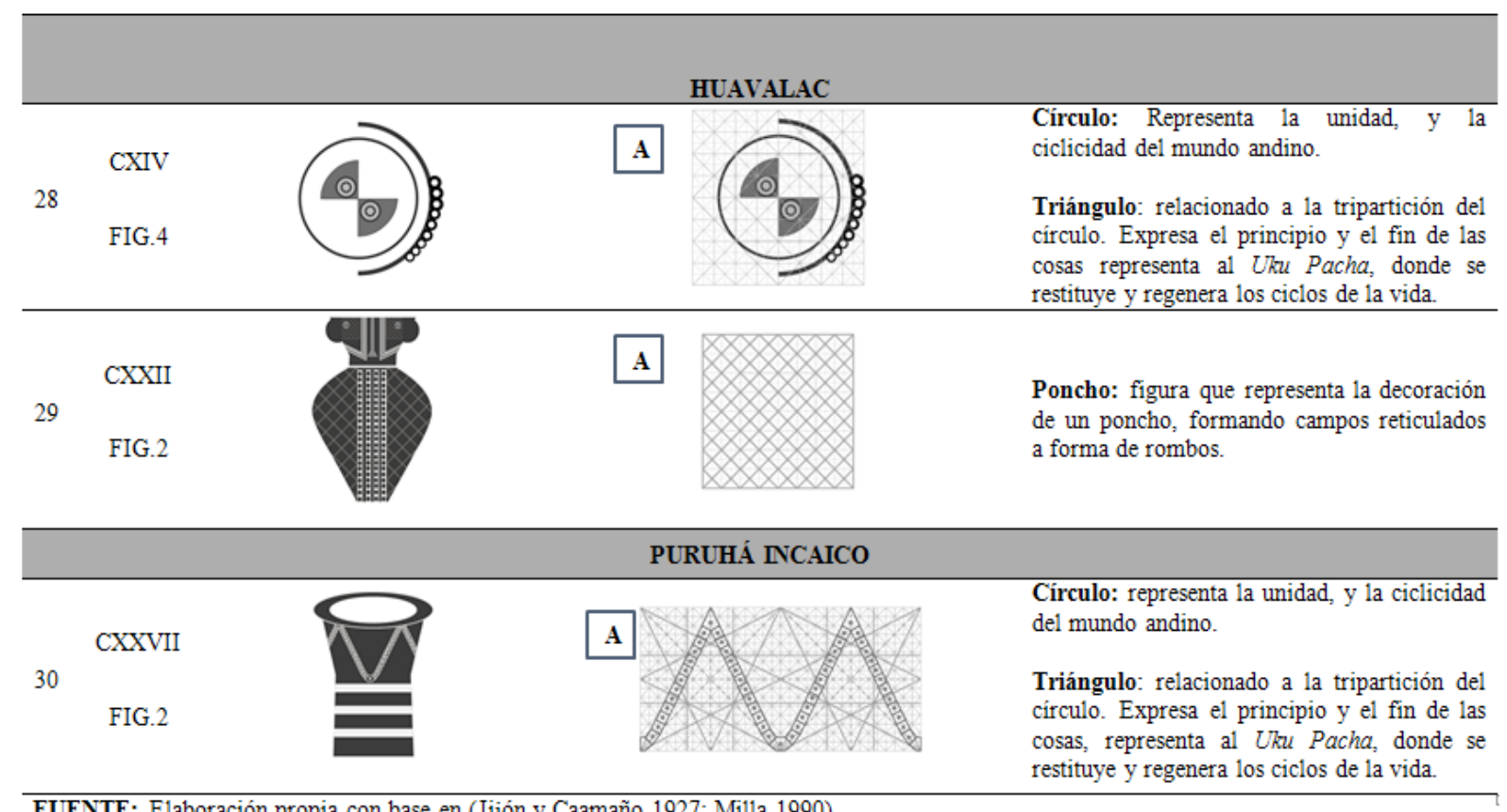

\section{Creación de sistemas modulares y súper modulares.}

Una vez lograda la abstracción de elementos representativos de la cultura Puruhá, inició el proceso de generación modular. Para esta experimentación, se cumplió una selección aleatoria de 10 módulos del banco digital de estudio y se desarrolló la matriz que se observa desde la figura 2 a 11.

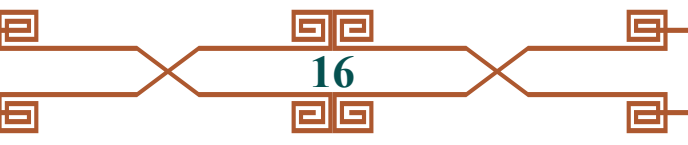


Figura 2: Matriz de generación modular - Estructura 01

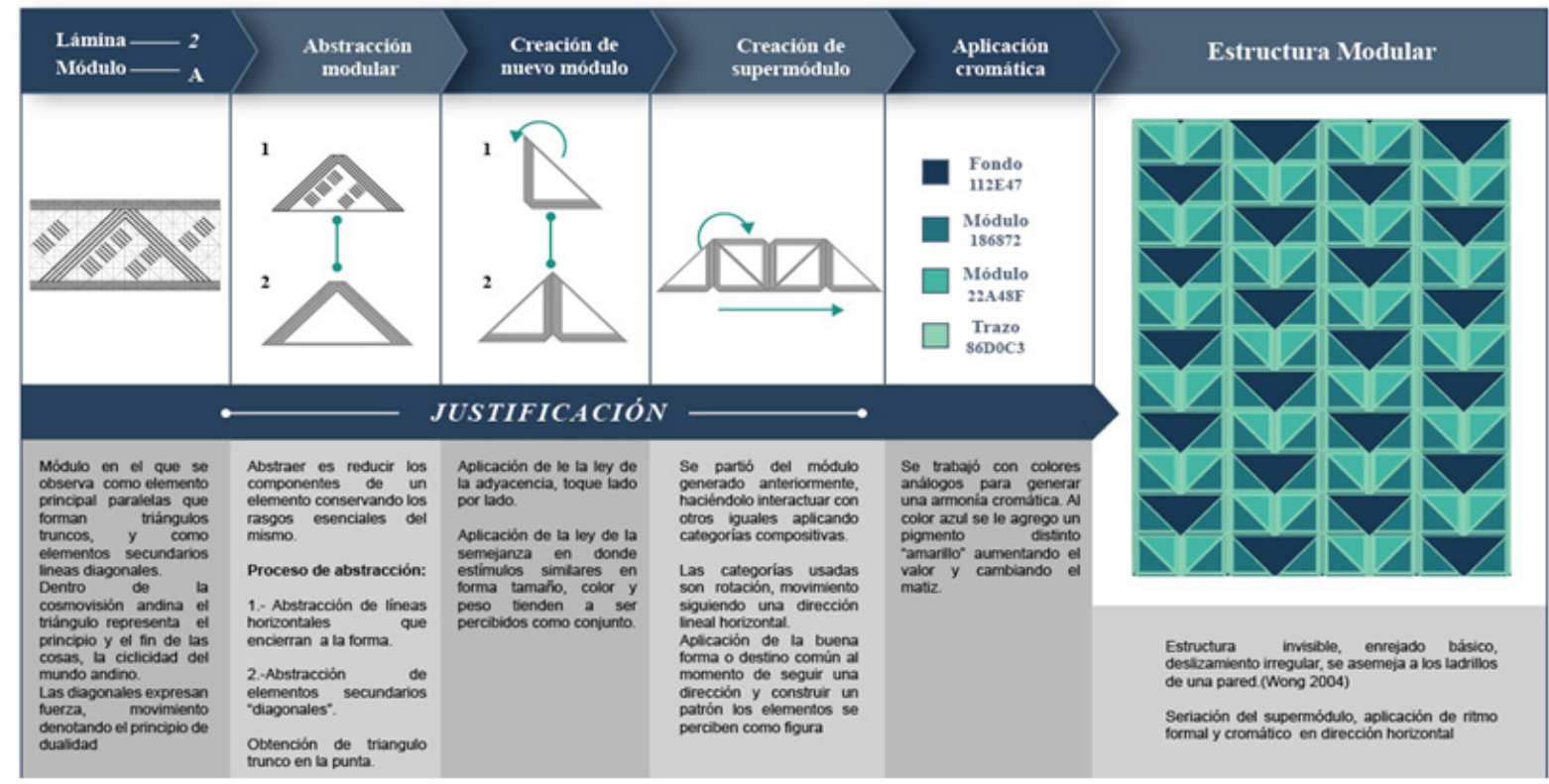

Fuente: Elaboración propia con base en (Jijón y Caamaño 1927; Milla 1990; Wertreimer, Kohler y Koffka 1923).

El súper módulo representa la reciprocidad andina. Se basa en la concepción de correspondencia, la creencia de que los actos realizados son supervisados por un ser superior.

Figura 3: Matriz de generación modular - Estructura 02

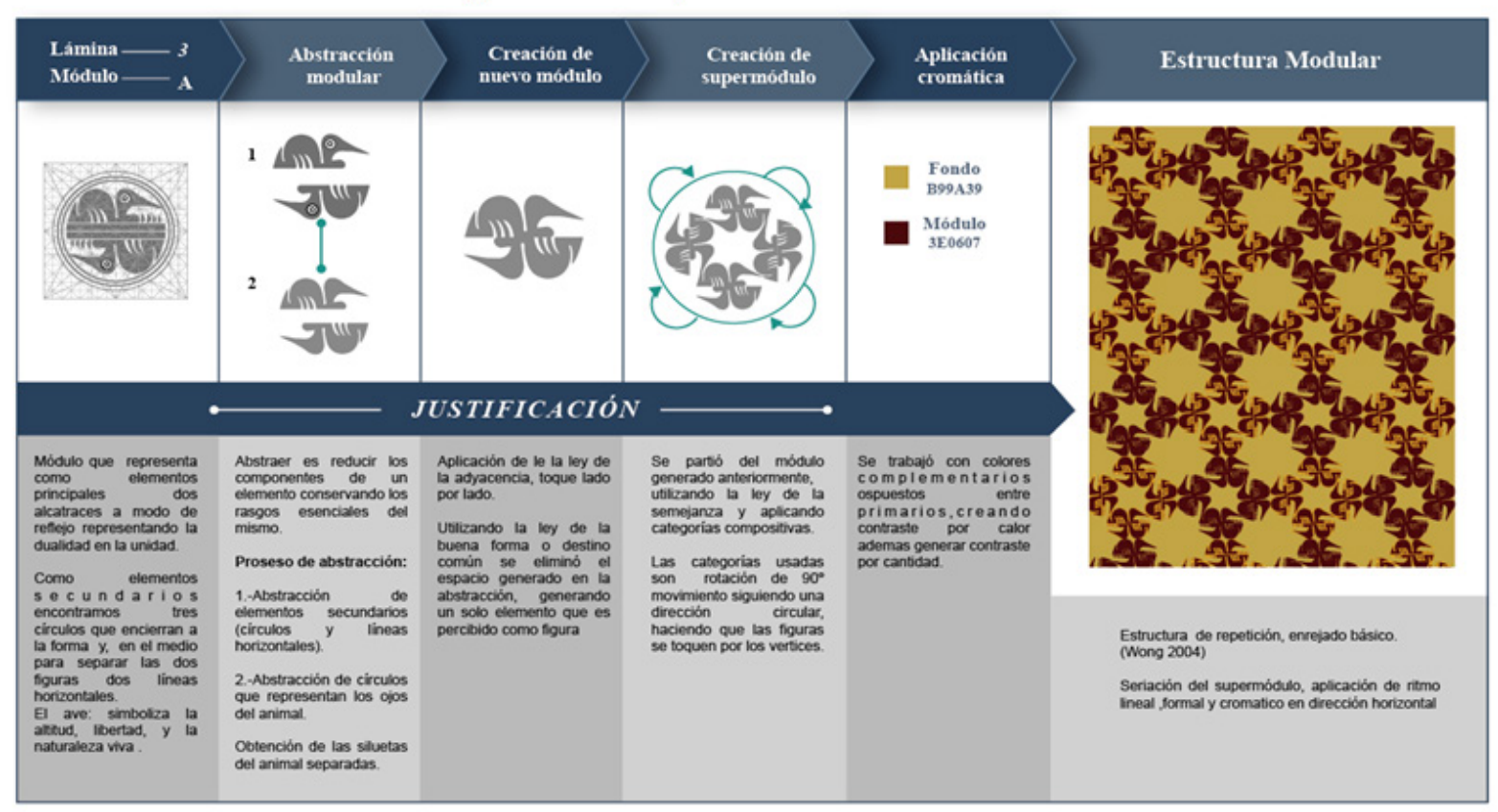

Fuente: Elaboración propia con base en (Jijón y Caamaño 1927; Milla 1990; Wertreimer, Kohler y Koffka 1923).

回 $>$ 回回


El súper módulo representa la naturaleza andina. Simboliza la altitud, libertad, y la naturaleza viva, presente en la cultura Puruhá, además de la interrelación del hombre con los animales.

Figura 4: Matriz de generación modular - Estructura 03

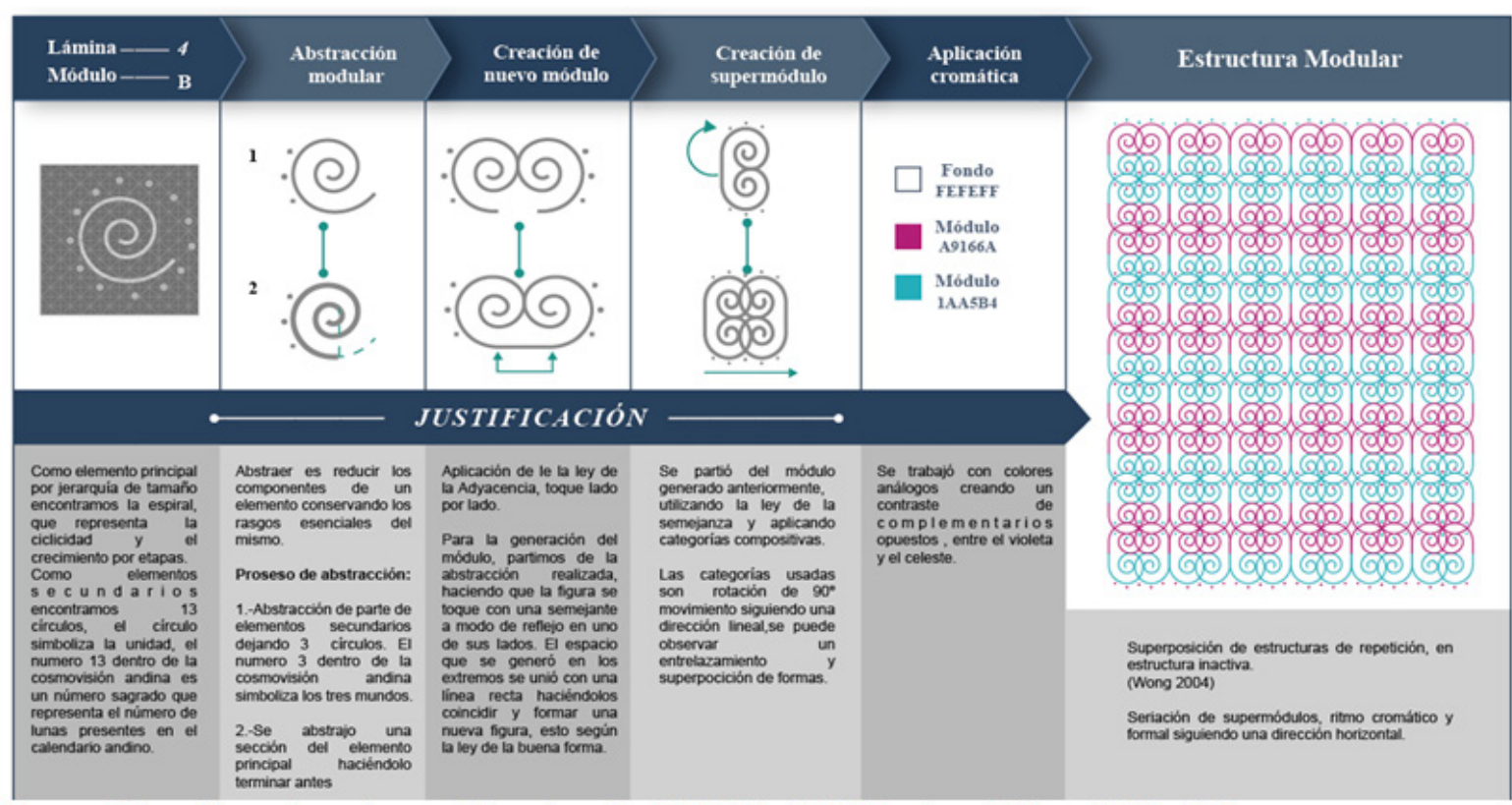

Fuente: Elaboración propia con base en (Jijón y Caamaño 1927; Milla 1990; Wertreimer, Kohler y Koffka 1923).

El súper módulo representa el florecimiento. Refiere a la concepción del tiempo, demostrando una interrelación entre el pasado y el presente. El tiempo de florecimiento en las cosechas.

Figura 5: Matriz de generación modular - Estructura 04

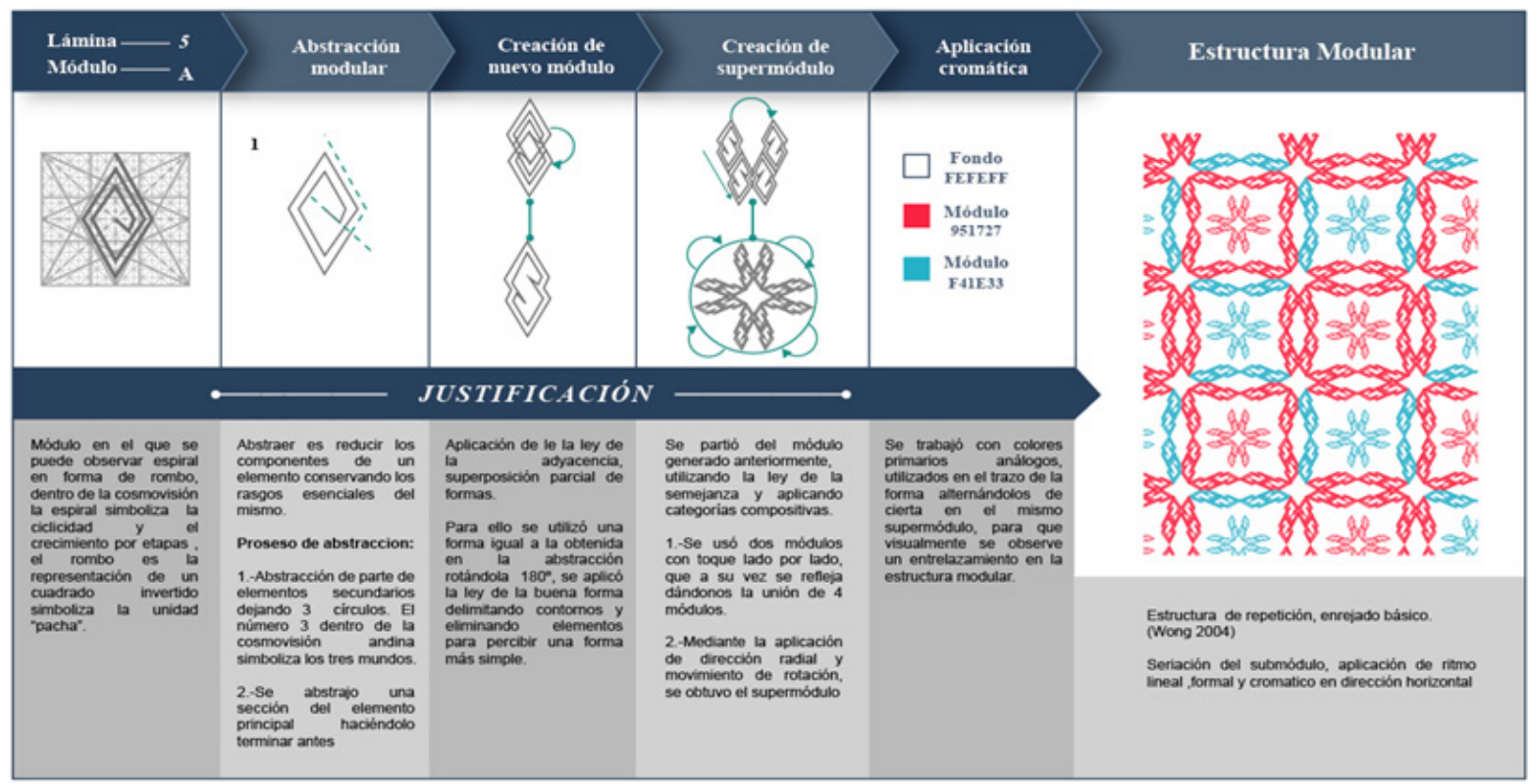

Fuente: Elaboración propia con base en (Jijón y Caamaño 1927; Milla 1990; Wertreimer, Kohler y Koffka 1923). 
El súper módulo representa la prosperidad. Refiere a los cuatro puntos cardinales, el tiempo de siembra y cosecha de productos agrícolas.

Figura 6: Matriz de generación modular - Estructura 05

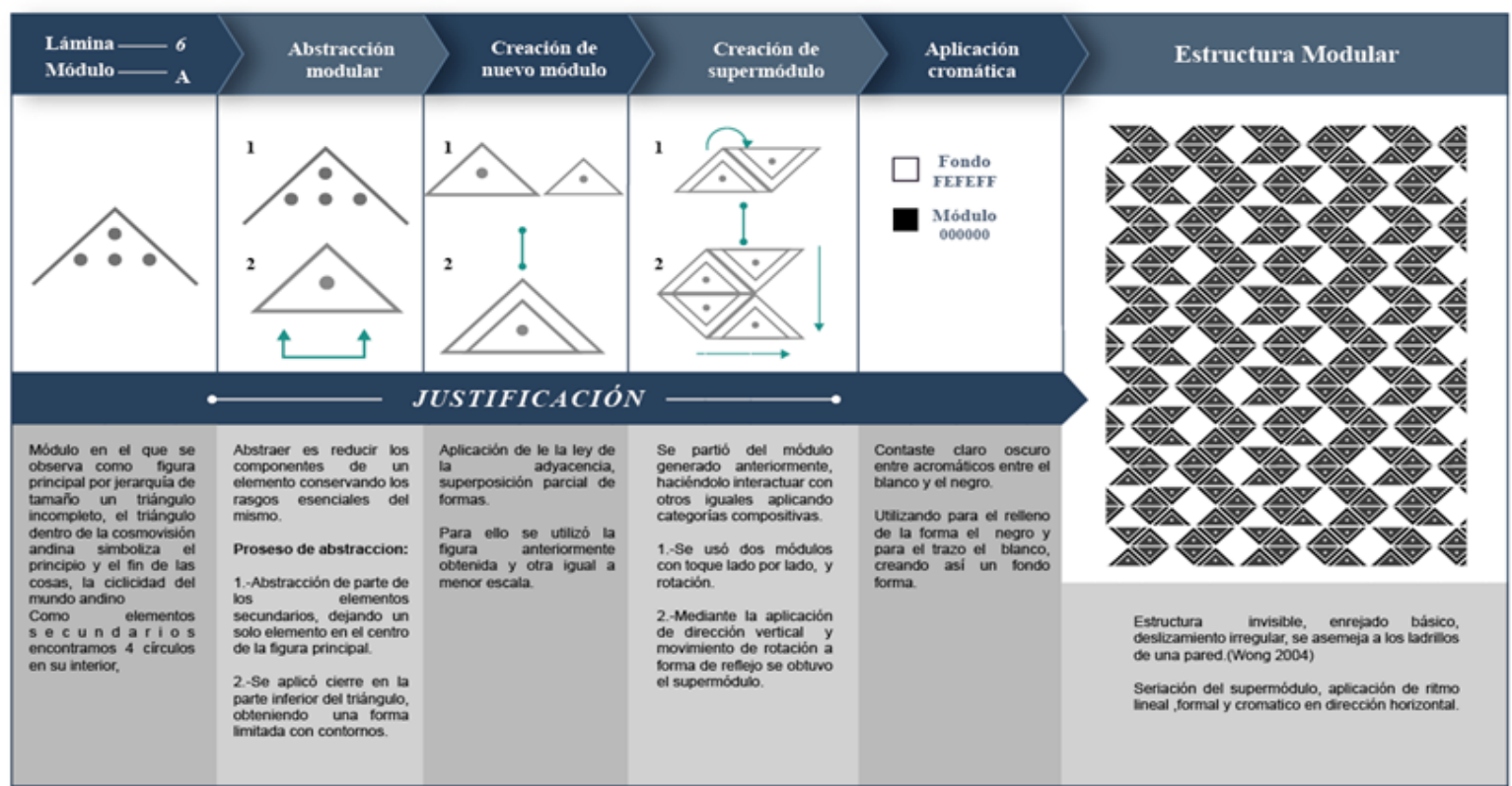

Fuente: Elaboración propia con base en (Jijón y Caamaño 1927; Milla 1990; Wertreimer, Kohler y Koffka 1923).

El súper módulo representa la dualidad y reciprocidad. Refiere a la diversidad que existe en la comunidad y a su vez, a los habitantes trabajando en conjunto, para caminar en un mismo sentido.

Figura 7: Matriz de generación modular - Estructura 06

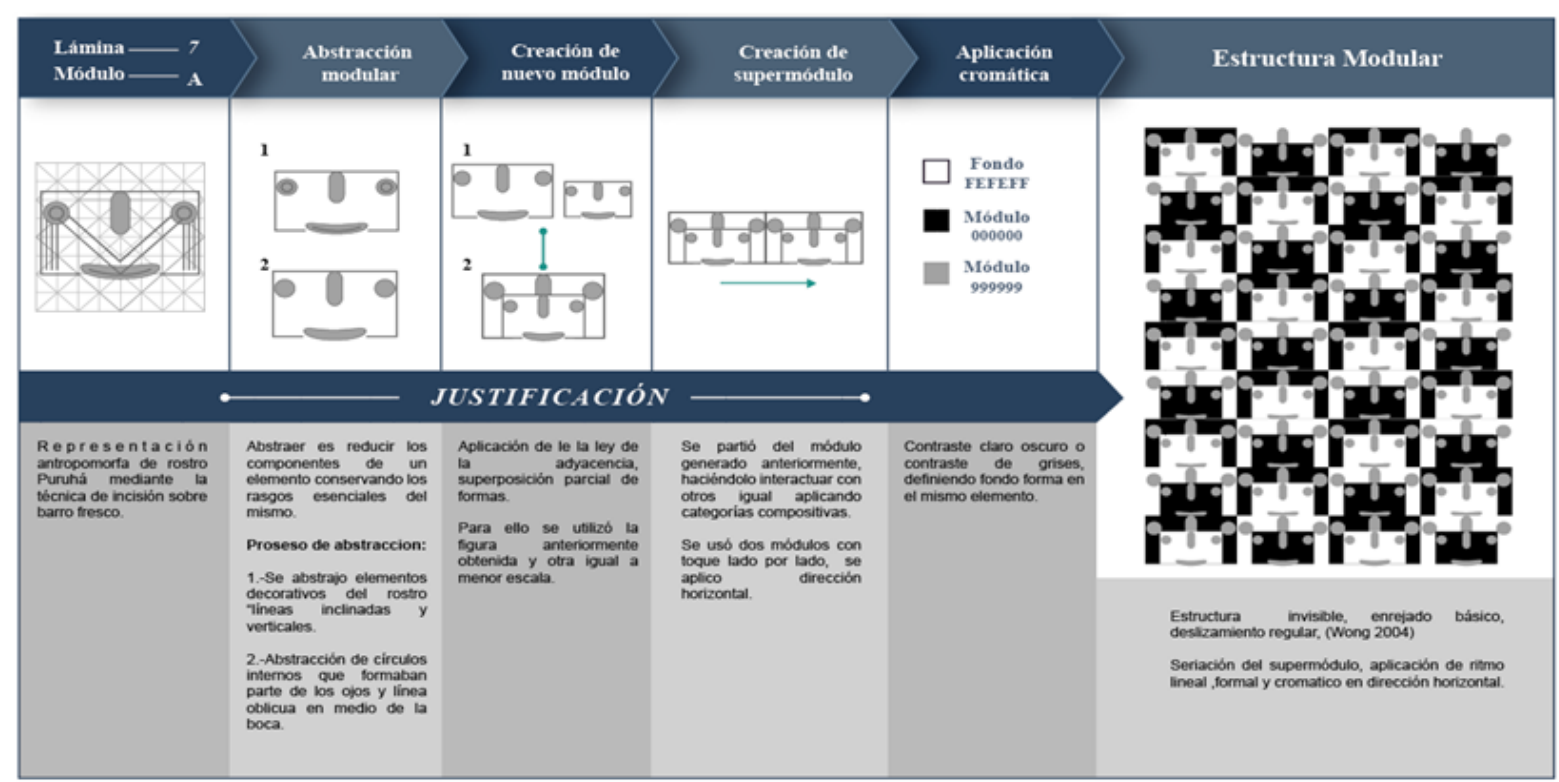

Fuente: Elaboración propia con base en (Jijón y Caamaño 1927; Milla 1990; Wertreimer, Kohler y Koffka 1923).

$\underset{\text { 回 }}{\frac{\text { 回回 }}{19}} \times \underset{\text { 回 }}{\text { 回 }}$


El súper módulo representa al sujeto andino o sujeto comunitario. Representa al runa y la interacción de este, dentro de la comunidad. La cultura Puruhá se formó mediante ayllus, la unión de varios de estos, conformaban pueblos. La estructura modular representa la conformación de la gran nación Puruhá.

Figura 8: Matriz de generación modular - Estructura 07

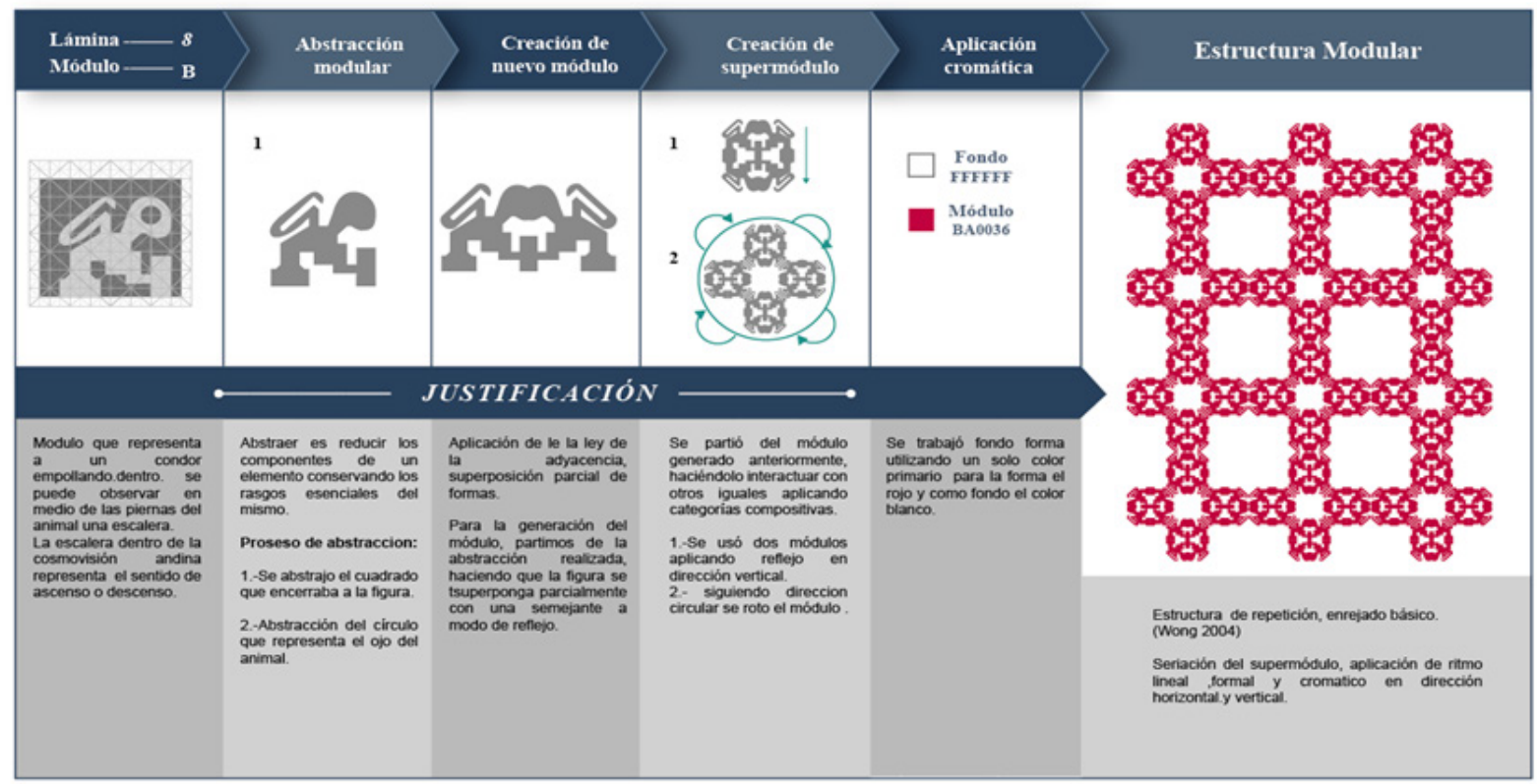

Fuente: Elaboración propia con base en (Jijón y Caamaño 1927; Milla 1990; Wertreimer, Kohler y Koffka 1923).

El súper módulo representa la naturaleza andina. Simboliza la altitud, libertad, y la naturaleza viva presente en la cultura Puruhá, además de la interrelación del hombre con los animales.

Figura 9: Matriz de generación modular - Estructura 08

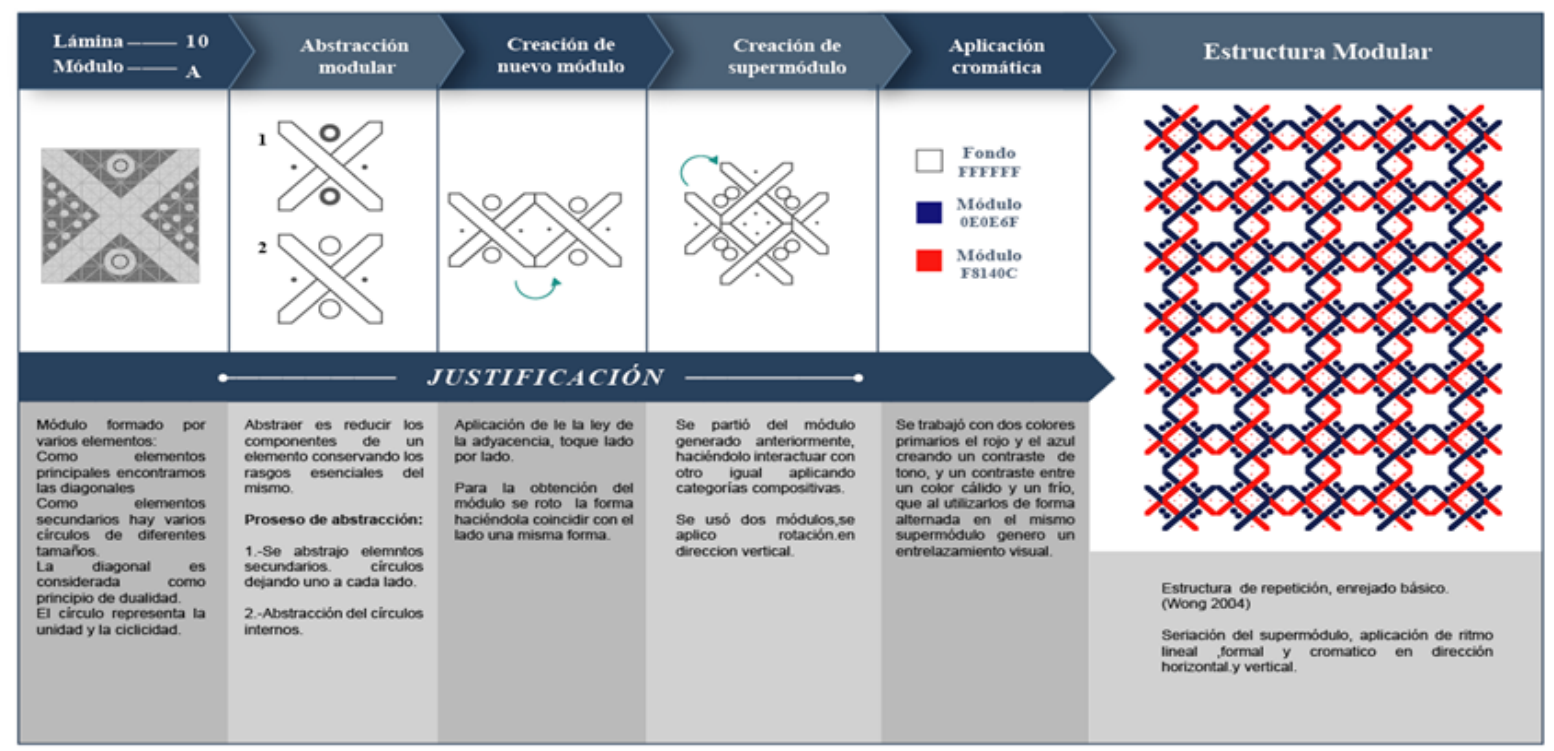

Fuente: Elaboración propia con base en (Jijón y Caamaño 1927; Milla 1990; Wertreimer, Kohler y Koffka 1923).

$\underset{\text { 回回 }}{\frac{\text { 回回 }}{20}} \times \underset{\text { 回 }}{\text { 回 }}$




\section{Unach}

El súper módulo representa la organización social. La cultura Puruhá en la antigüedad vivía en construcciones tipo colmena, habitadas por ayllus o clanes.

Figura 10: Matriz de generación modular - Estructura 09

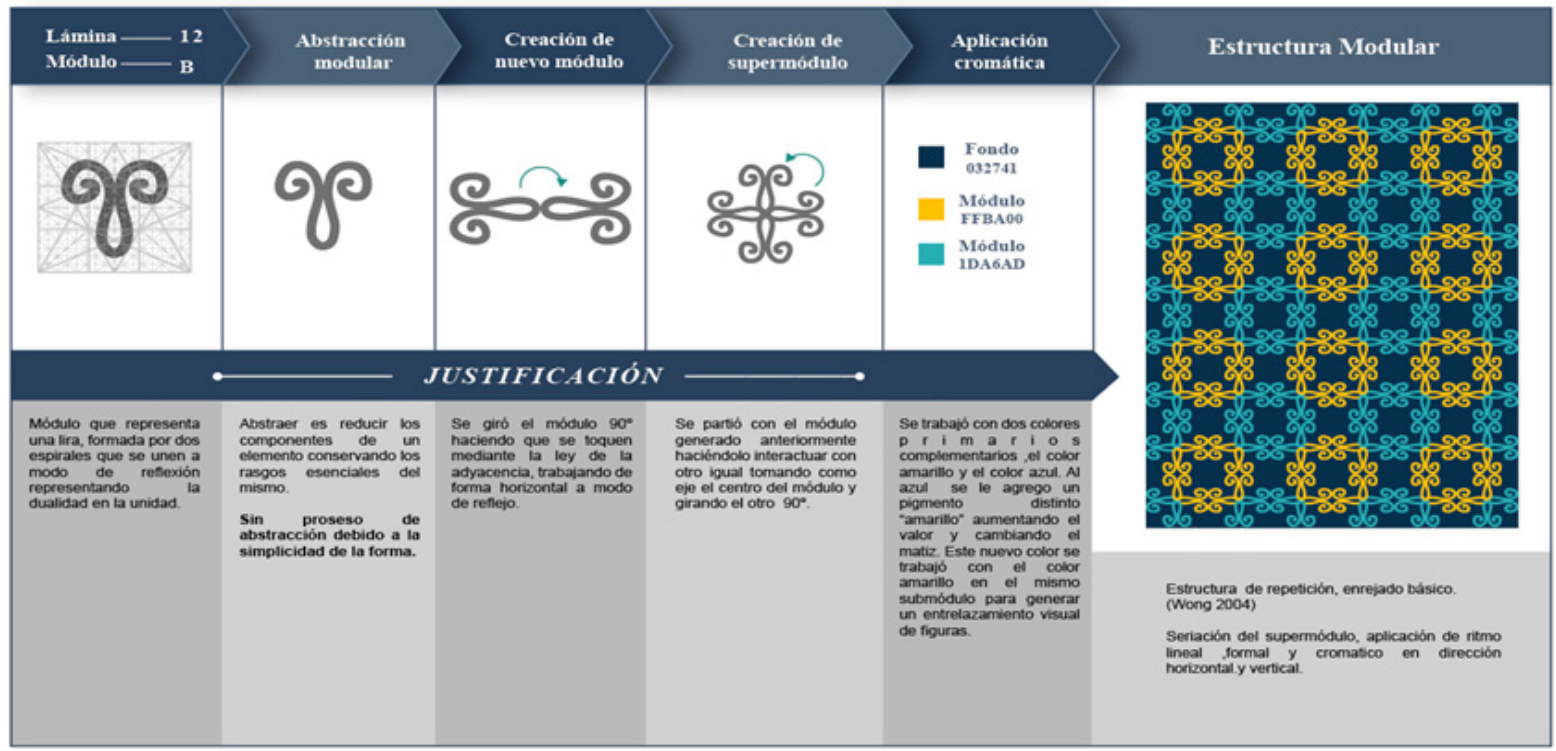

Fuente: Elaboración propia con base en (Jijón y Caamaño 1927; Milla 1990; Wertreimer, Kohler y Koffka 1923).

El súper módulo representa la feminidad. Simboliza inocencia y pureza de la mujer Puruhá, además expresa la relación entre el hombre y la naturaleza.

Figura 11: Matriz de generación modular - Estructura 10

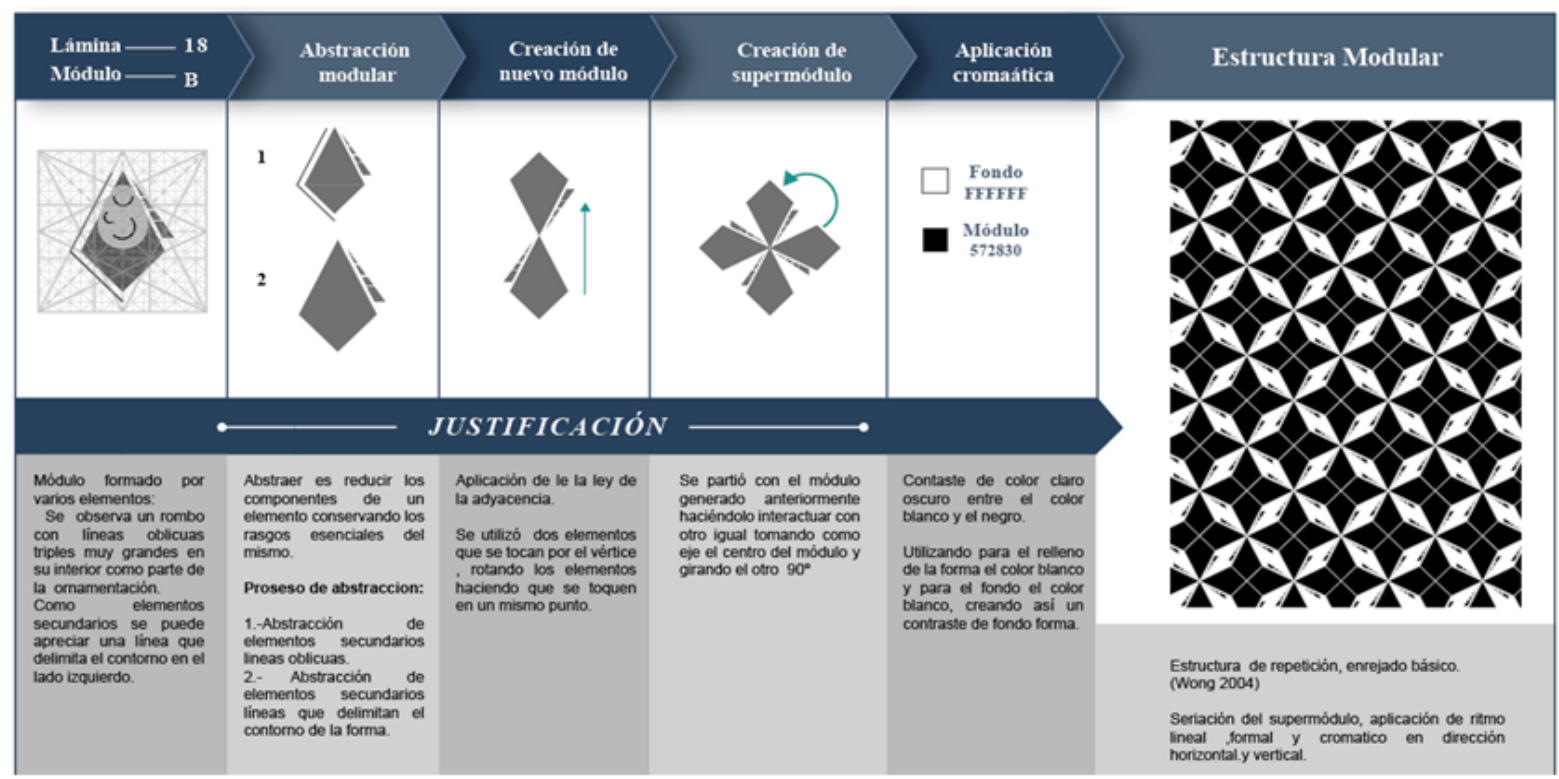

Fuente: Elaboración propia con base en (Jijón y Caamaño 1927; Milla 1990; Wertreimer, Kohler y Koffka 1923).

El súper módulo representa la festividad. La cultura Puruhá tiene como costumbre la celebración de los cuatro Raymis. Relacionado también con el buen vivir. 


\section{Aplicación de leyes y categorías de diseño}

Aportó en la innovación del módulo original, permitiendo realizar composiciones dinámicas, funcionales y prácticas. Estas composiciones pueden ser utilizadas en distintos soportes o piezas visuales. La cromática utilizada se trabajó bajo criterios de contrastes cromáticos propuestos por Johannes Itten, en los que nos dan siete posibilidades de contraste que son: contraste de color en sí mismo, complementario, contraste de claro oscuro, cálido frío, simultáneo, de calidad; por último, contraste de cantidad. (sf:33).

Los ejercicios experimentales de aplicación se presentan en distintos tipos de soportes, utilizando diversos medios de reproducción, como la impresión láser, sublimado, serigrafía, pi- rograbado, entre otros. Los soportes elegidos están direccionados a un público objetivo juvenil, dada la intencionalidad de los autores, quienes pretenden incidir en hombres y mujeres, exigentes a la hora de vestir o adquirir un suvenir. Considerando, además, que este público objetivo es más vulnerable a un proceso de aculturación. Con el desarrollo de las piezas gráficas propuestas, se pretende incidir en la atmósfera visual, dando valor a la iconografía Puruhá, en un contexto iconográfico saturado de íconos norteamericanos y europeos.

Los diseños finales, al ser trabajados bajo leyes y categorías compositivas, poseen dinamismo, haciéndolos versátiles y útiles para la difusión en distintos soportes gráficos, tanto físicos como digitales, como se muestran en las figuras 12 a 18 .

Figura 12: Soporte digital - Fondo de pantalla - Estructura 01

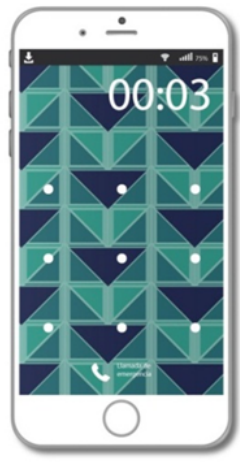

Fuente: Elaboración propia con base en (Jijón y Caamaño 1927; Milla 1990; Wertreimer, Kohler y Koffka 1923).

Figura 13: Pirograbado Bisutería- Estructura 02

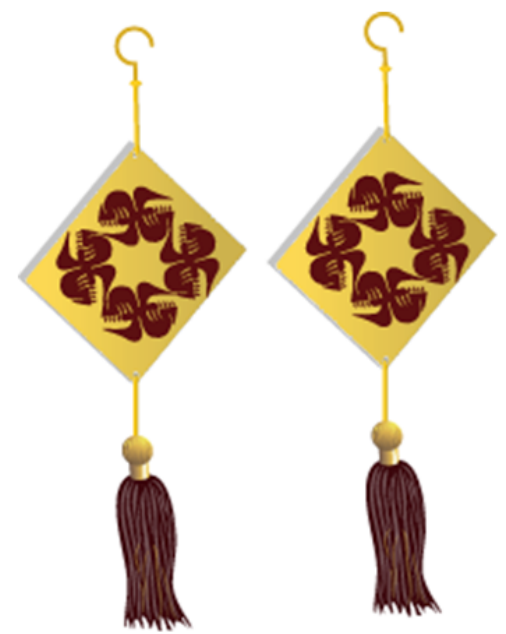

Fuente: Elaboración propia con base en (Jijón y Caamaño 1927; Milla 1990; Wertreimer, 
Figura 14: Impresión láser en portada de cuademo - Estructura 03

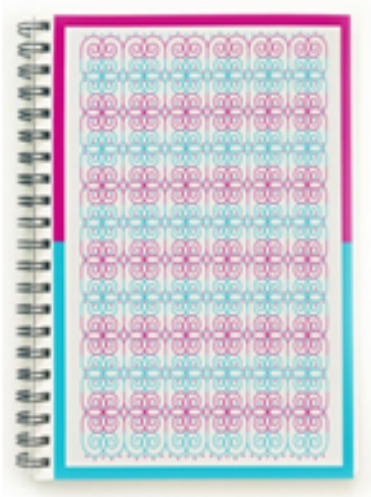

Fuente: Elaboración propia con base en (Jijón y Caamaño 1927; Milla 1990; Wertreimer, Kohler y Koffka 1923).

Figura 15: Decoración en taza cerámica - Estructura 04

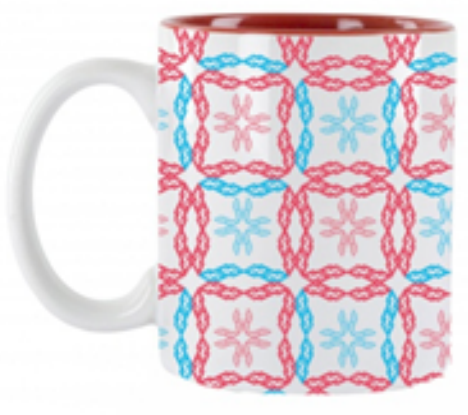

Fuente: Elaboración propia con base en (Jijón y Caamaño 1927; Milla 1990; Wertreimer, Kohler y Koffka 1923).

Figura 16: Impresión serigrafía en camiseta - Estructura 05

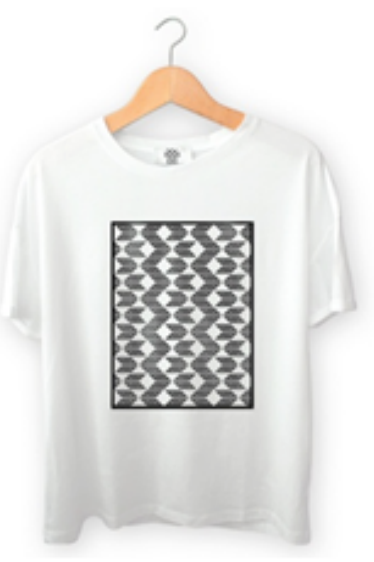

Fuente: Elaboración propia con base en (Jijón y Caamaño 1927; Milla 1990; Wertreimer, Kohler y Koffka 1923).

\begin{tabular}{|c|c|c|}
\hline 包 & 回回 & 回 \\
\hline 叫 & $\begin{array}{c}23 \\
\text { 回回 }\end{array}$ & \\
\hline
\end{tabular}


Figura 17: Bordado en tela - Estructura 07

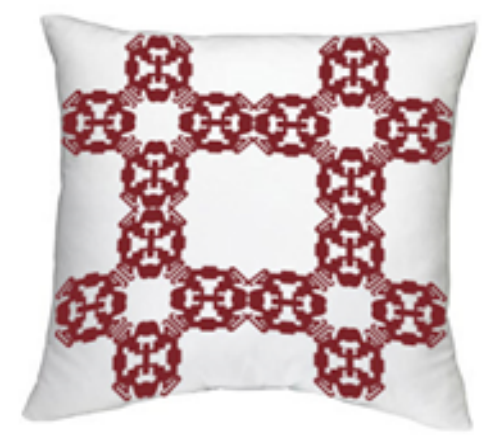

Fuente: Elaboración propia con base en (Jijón y Caamaño 1927; Milla 1990; Wertreimer, Kohler y Koffka 1923).

Figura 18: Diseño de calzado - Estructura 09

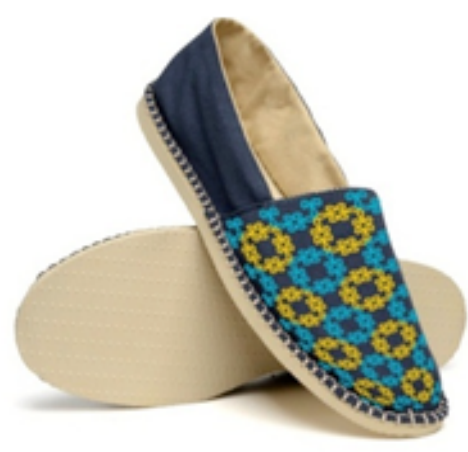

Fuente: Elaboración propia con base en (Jijón y Caamaño 1927; Milla 1990; Wertreimer, Kohler y Koffka 1923). 


\section{CONCLUSIONES}

Con base al análisis semiótico de las piezas cerámicas de la Cultura Puruhá, en textos relacionados a esta investigación, se concluye que en los elementos visuales de esta cultura predominan los cántaros antropomorfos pertenecientes mayormente al periodo Elén Pata, en los que se encuentran íconos representativos como el triángulo, diagonales, espirales dobles, círculos, además de íconos que representan al sol, al cóndor y a la serpiente.

Las 30 fichas semióticas evidencian la riqueza iconográfica de la cultura Puruhá. Visualiza además los principios de la cosmovisión andina, como: dualidad antagónica o complementaria, reciprocidad, soporte de la existencia y la complementariedad o vinculariedad, explicados por Josef Estermann (1998); estos principios son universales para el sujeto andino. Además, las estructuras compositivas evidenciadas en los vestigios cerámicos, se ajustan a los principios cosmológicos expresados en el Altar de Corincacha, que subdivide al mundo en tres partes: Hanan, Kai y Uku Pacha. Evidencias iconografía zoomorfa preponderante como la serpiente bicéfala, mencionada en los textos, como la especie capaz de atravesar los tres mundos.

Otras expresiones iconográficas están asociadas a los cuatro raymis principales: solsticio de verano -21 de junio-, equinoccio de otoño -22 de marzo-, solsticio de verano -22 de diciembre- y equinoccio de primavera -22 de septiembre. El concepto se consolida con la evocación de los cuatro elementos: viento, agua, tierra y fuego. Estos preceptos filosóficos fundamentan los sistemas compositivos de Milla; la bipartición y tripartición armónica.
La creación de una matriz de generación modular, fundamentada en leyes y categorías compositivas, al igual que, la invención de sistemas modulares a partir de interpretaciones semióticas de iconografía andina, contribuyen al diseño de composiciones visuales. Los conceptos creativos, se fundamentan en expresiones culturales de origen Puruhá, evidenciando de esta manera, la utilización de recursos gráficos prehispánicos en diseños contemporáneos, utilizando distintos soportes y medios de reproducción.

La investigación, contextualizada en las propuestas conceptuales de semiólogos andinos, permite fundamentar un nuevo estilo de ilustración de vestigios cerámicos, desde enfoques técnicos del Diseño. Sin desconocer los protocolos propuestos desde la Arqueología, que, si bien analiza los mismos vestigios, sus resultados no están en la misma línea de los análisis propuestos desde la gráfica.

Los diseñadores gráficos, alineados a los objetivos del Plan Nacional del Buen Vivir, deben propender a generar emprendimientos culturales, que pongan en valor la iconografía de las culturas prehispánicas del Ecuador. La abstracción semiótica es un método válido para visualizar la iconografía de las culturas, utilizándolas en piezas gráficas contemporáneas, en soportes digitales como físicos. 


\section{REFERENCIAS BIBLIOGRÁFICAS}

Benítez, L., \& Garcés, A. (1988). Culturas Ecuatorianas de ayery hoy. Quito, Ecuador: Abya Yala.

Estermann, J. (1998). Filosofia Andina. Estudio intercultural de la sabiduría autóctona andina. Quito, Ecuador: Ediciones Abya Yala.

Carretero, P., \& Samaniego, W. (2017). Prospección arqueológica en el sitio Puruhá de Collay, Riobamba, Ecuador. Arqueología Iberoamericana 33, 18-26. Recuperado de: http://purl.org/aia/333.

Eco, U. (1976). Tratado de semiótica general. Barcelona: Lumen.

Ferrer, A., \& Gómez, D. (2013). Imagen y comunicación visual. Universitat Oberta de Catalunya.

González, A. (2015) Los métodos de investigación. Presentación ppt. para la Universidad Nacional de Chimborazo.

Haro, S. (1977). Puruhá Nación Guerrera. Quito, Ecuador: Editora Nacional.

Pereira, Z. (2011) Los diseños de método mixto en la investigación en educación: Una experiencia concreta. Revista Electrónica Educare. XV(1), 1529. Recuperado de. http://www.redalyc.org/ html/1941/194118804003/

Idrobo, X. (2006). Diseño Bidinensional. Riobamba, Ecuador: Escuela Superios Politécnica de Chimborazo.

Itten, J. (s.f.). El arte del color edición abreviada. Rue Cassett- París: Bouret.

Jijón y Camaño, J. (1927). Puruhá. Contibución al conocimiento de los aborigenes de la provincia de Chimborzo de la Repúbica del Ecuador. Quito: Tipografía y Encuadernación Salesianas.

Kottak, P. (2011). Antropología Cultural. Ney York, U.S.A: Mc Graw Hill companies, Inc.

Milla, C. (1986). "Génesis de la cultura Andina”. Perú: Editorial CAP. Colección Bienal.

Milla, Z. (1990). Introducción a la semiótica del diseño andino precolombino. Lima, Perú: Asociación de investigación y comunicación Cultural Amaru Wayra.

Pérez, A. (1978). Los Puruhuayes. Quito, Ecuador.

Salguero, R. (2015). Etnografía como método de investigación aplicado al Diseño Gráfico. Actas del Diseño. Universidad de Palermo. Buenos Aires, Argentina.

Salguero, R. (2018). Evolución histórica del proceso de enseñanza del Diseño en el contexto mundial. Tesis Doctoral -Manuscrito en preparación-. Universidad Pedagógica Enrique José Varona. La Habana. Cuba.

Wong, W. (2004). Fundamentos del diseño bi- y tri- dimensional. (H. A. Thevenet, Trad.) Barcelona España: Gustavo Gili, S. A.
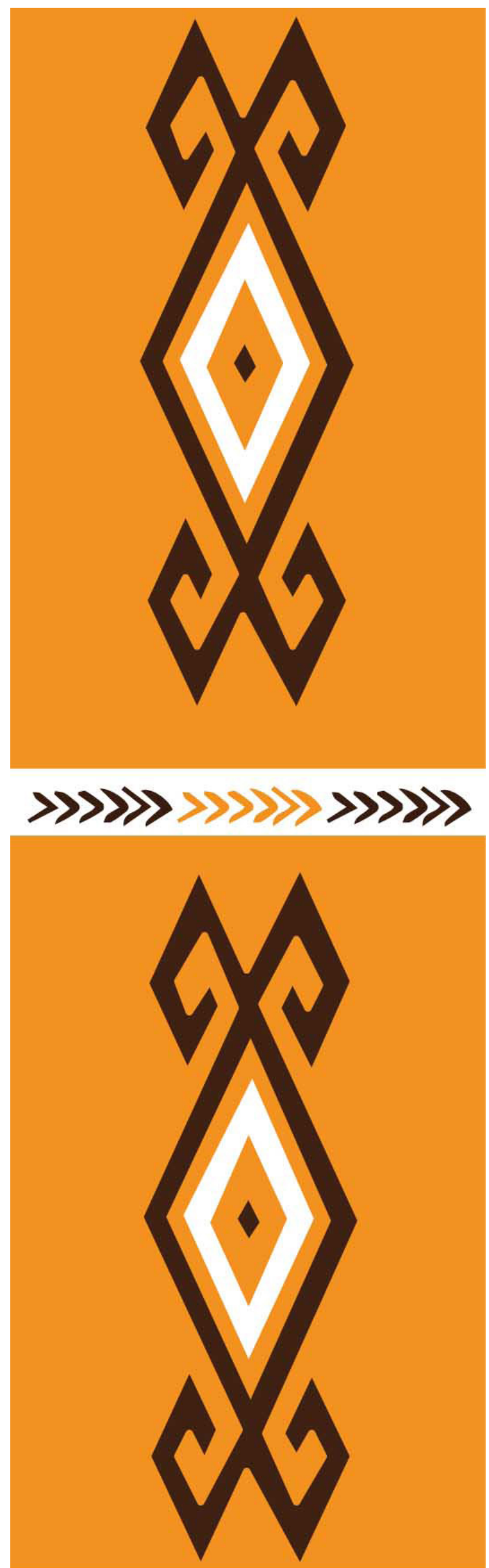